\title{
HUBUNGAN ANTARA KONFLIK PERAN GANDA DENGAN STRES KERJA PADA PEGAWAI WANITA YANG SUDAH MENIKAH DI UNIVERSITAS MALAHAYATI BANDAR LAMPUNG
}

\author{
Prida Harkina ${ }^{1}$, Junaidi ${ }^{1}$, Supriyati ${ }^{2}$, Monica Prita Sari ${ }^{3}$ \\ ${ }^{1}$ Departemen Psikologi Klinis Fakultas Kedokteran Universitas Malahayati \\ ${ }^{2}$ Departemen Psikologi Industri Fakultas Kedokteran Universitas Malahayati \\ ${ }^{3}$ Program Studi Psikologi Fakultas Kedokteran Universitas Malahayati
}

[Email Korespondensi : monicapritasari@gmail.com]

\begin{abstract}
The Correlation of Double Role Conflict With Stress Work on Married Woman Employees at Malahayati University Bandar Lampung. Work stress is an individual's dynamic condition in the face of opportunities, constraints, or demands, associated with what is highly desirable and the result is perceived as uncertain but important. Dual role conflict is a form of inter-role conflict where the pressures of roles from the domain of work and family conflict with each other. This study aims to find out the relationship between dual role conflict and work stress in married female employees at Malahayati University Bandar Lampung. The method in this study uses cross sectional approach. The population in this study was female employees who were married and had children aged 0-12 years. Sampling techniques in this study using purposive sampling techniques as many as 42 people. Based on the results of data analysis, the results obtained there is a relationship between dual role conflict and work stress (Rxy 0.719 with Sig 0.000 where $p<0.000$ ). Based on the results of the analysis it can be concluded that the hypotheses proposed in this study are acceptable. This means that the higher the double role conflict, the higher the work stress and vice versa the lower the double role conflict, the lower the work stress.
\end{abstract}

Keywords: Double Role Conflict, Job Stress, Married Female Employees

\begin{abstract}
Abstrak: Hubungan Konflik Peran Ganda Dengan Stres Kerja Pada Pegawai Wanita yang Sudah Menikah di Universitas Malahayati Bandar Lampung. Stres kerja adalah suatu kondisi dinamik individu dalam menghadapi peluang, kendala, atau tuntutan, yang terkait dengan apa yang sangat diinginkan dan hasilnya dipersepsikan sebagai sesuatu yang tidak pasti tetapi penting. Konflik peran ganda merupakan suatu bentuk konflik peran antar dimana tekanan peran dari domain pekerjaan dan keluarga saling bertentangan. Penelitian ini bertujuan untuk mengetahui hubungan antara konflik peran ganda dengan stres kerja pada pegawai wanita yang sudah menikah di Universitas Malahayati Bandar Lampung. Metode pada penelitian ini menggunakan pendekatan cross sectional. Populasi pada penelitian ini adalah seluruh pegawai wanita yang sudah menikah dan mempunyai anak usia 0-12 tahun sesuai ciri-ciri tertentu. Teknik pengambilan sampel pada penelitian ini menggunakan teknik Purposive Sampling sebanyak 42 orang. Berdasarkan hasil analisis data, diperoleh hasil terdapat hubungan antara konflik peran ganda dengan stress kerja (Rxy 0.719 dengan Sig 0.000 dimana $p<0.000$ ). Berdasarkan hasil analisis dapat disimpulkan bahwa hipotesis yang diajukan dalam penelitian ini dapat diterima. Artinya semakin tinggi konflik peran ganda maka semakin tinggi stress kerja dan sebaliknya semakin rendah konflik peran ganda maka semakin rendah stress kerja.
\end{abstract}

Kata Kunci: Konflik Peran Ganda, Stres Kerja, Pegawai Wanita Yang Sudah menikah 


\section{PENDAHULUAN}

Kebutuhan hidup manusia dengan mengikuti pergerakan waktu akan semakin banyak dan bertambah. Kebutuhan primer manusia yang terdiri dari pangan, sandang dan papan merupakan kebutuhan utama yang harus dipenuhi untuk dapat hidup wajar. Orang yang hidup di bawah garis kemiskinan dapat di indikasikan apabila dia merasa kurang puas atas apa yang sudah dia dapatkan. Seseorang harus memiliki penghasilan agar dapat memenuhi semua kebutuhan hidupnya. Peningkatan jumlah angkatan kerja wanita dalam Demografi. Dari total populasi 112 juta jumlah pekerja di Indonesia, saat ini ada 43 juta pekerja perempuan yang membantu pertumbuhan ekonomi Indonesia. Artinya, jumlah pekerja perempuan hampir sama besarnya dengan pekerja laki-laki di dunia. Keikutsertaan wanita dalam dunia kerja dapat dikatakan sudah meningkat sejak tahun 1960-an (U.S Cencus Bureau, 2003).

Kebutuhan hidup yang meningkat pada saat ini, yang tidak dapat dipenuhi hanya dari pendapatan suami sebagai kepala rumah tangga, membuat sebagian besar wanita akhirnya memutuskan untuk ikut serta bekerja guna mencukupi kebutuhan keluarga. Peran ganda yaitu sebagai ibu dan istri dirumah dan juga sebagai seorang pegawai ditempat kerja menjadi fenomena yang sering kita jumpai dalam dunia kerja, dimana tidak sedikit kaum wanita yang berpartisipasi dalam dunia industri. Konflik Peran Ganda merupakan bentuk konflik peran dimana tuntutan peran dari pekerjaan dan keluarga tidak dapat sejajar dikarenakan pada saat seseorang berusaha memenuhi pemenuhan tuntutan peran dalam keluarga dipengaruhi oleh kemampuan orang dalam memenuhi tuntutan pekerjaan (Frone, 2010).

Sebagai ibu rumah tangga dan sebagai seorang pekerja yang menjalani 2 peran ganda tidaklah mudah. Pegawai wanita yang belum menikah memiliki peran dan tanggung jawab yang lebih ringan dibandingkan dengan pegawai wanita yang sudah menikah dan sudah mempunyai anak yang mengalami peran ganda karena wanita tersebut berperan dalam pekerjaannya dan juga berperan di dalam keluarga. Kegagalan individu beradaptasi di lingkungan kerja yakni terjadi ketidaksesuaian antara harapan dan kenyataan yang merupakan reaksi emosi dan fisik adalah stres yang terjadi ditempat kerja. Seseorang merasa sakit dan tidak nyaman karena pekerjaannya atau ditempat kerja dan dalam situasi tertentu. Stres kerja adalah konflik peran dan beban kerja yang berlebihan yang mengganggu prestasi dan kemampuan individu untuk bekerja (Kinnunen, $U$ dkk, 2006).

Menurut Hotman \& Minarsih (2011), konflik peran ganda dan stres kerja merupakan dua variabel yang saling berkaitan.Stres kerja muncul apabila seseorang tidak mampu mengelola atau mengatasi konflik yang terjadi di lingkungan kerjanya, dikarenakan waktu pada pekerjaan dan keluarga saling bertentangan, dan konflik pekerjaan pada pegawai lebih banyak waktu dikantor dibandingkan waktu dengan keluarga (Hotman \& Minarsih, 2011). Dunia kerja beban kerja yang tinggi merupakan permasalahan yang sering dijumpai semakin meningkatnya beban kerja yang dialami pegawai karena tuntutan profesionalisme berimplikasipada munculnya tekanan-tekanan psikologis berupa stres pekerjaan yang disebabkan oleh beban kerja dan kondisi kerja (Martini, 2017).

Berdasarkan latar belakang dan permasalahan tersebut, maka dapat diasumsikan bahwa konflik peran ganda memiliki hubungan dengan stres kerja sehingga rumusan masalah dari penelitian ini adalah "Apakah terdapat hubungan antara konflik peran ganda dengan stres kerja pada pegawai wanita yang sudah menikah di Universitas Malahayati?" 


\section{METODE}

Jenis penelitian ini adalah penelitian analitis dengan pendekatan cross sectional yang bertujuan untuk mengetahui Apakah terdapat hubungan antara konflik peran ganda dengan stres kerja pada pegawai wanita yang sudah menikah di Universitas Malahayati. Populasi pada penelitian ini adalah seluruh pegawai wanita yang sudah menikah dan mempunyai anak usia 0-12 tahun sesuai ciri-ciri tertentu sebanyak 42 orang. Pengambilan dalam penelitian ini menggunakan teknik Purpossive Sampling. Pengumpulan data Variabel Terikat $(Y)$ (Stres Kerja) dan Variabel Bebas (X) (Konflik Peran Ganda) dengan menggunakan kuesioner.

Metode pengumpulan data pada penelitian menggunakan skala psikologi dengan model skala Likert, dengan modifikasi alternative jawaban menjadi empat respon Sangat Setuju (SS), Setuju (S), Tidak Setuju (TS), Sangat Tidak Setuju (STS), yang terdiri dari pernyataan yang favorable (mendukung) dan unfavorable (tidak mendukung). Skala Konflik Peran Ganda merupakan suatu bentuk konflik peran antar dimana tekanan peran dari domain pekerjaan dan keluarga saling bertentangan yang diungkap dengan skala konflik peran ganda yang terdiri dari 3 aspek yaitu time-based conflict, strain-based conflict, behavior-based conflict. Skala Konflik Peran Ganda berjumlah 24 item pernyataan terdiri atas 13 item favorable dan 11 item unfavorable. Setiap item memiliki empat alternatif jawaban yaitu Sangat Setuju (SS), Setuju (S), Tidak Setuju (TS), Sangat Tidak Setuju (STS).

Skala Stres Kerja yang digunakan untuk mengungkap Stres Kerja, peneliti menggunakan skala yang dikembangkan oleh Pradita A.C (2016) dan Prihatini L.D (2017), berdasarkan aspek-aspek stres kerja yaitu aspek fisiologis, aspek psikologis, aspek tingkah laku, dan aspek organisasional pada teori Rice \& Robbins (1999). Skala Stres Kerja berjumlah 20 item pernyataan terdiri atas 10 item favorable dan 10 item unfavorable.Setiap item memiliki empat alternatif jawaban yaitu Sangat Setuju (SS), Setuju (S), Tidak Setuju (TS), Sangat Tidak Setuju (STS) (Rice \& Robbins, 1999).

Dalam penelitian ini analisis data akan menggunakan teknik statistik korelasi product moment. Jenis data dalam penelitian ini berupa data interval yaitu data kuantitatif atau data yang berupa angka (Sugiyono, 2012).

\section{HASIL}

Tabel 1. Distribusi Karakteristik Responden Berdasarkan Usia

\begin{tabular}{cccc}
\hline No & $\begin{array}{c}\text { Kelompok Usia } \\
\text { (tahun) }\end{array}$ & $\begin{array}{c}\text { Frekuensi } \\
(\mathrm{N})\end{array}$ & $\begin{array}{c}\text { Persen } \\
(\%)\end{array}$ \\
\hline 1 & $<36$ & 14 & 33,3 \\
2 & $36-44$ & 24 & 57,1 \\
3 & $>44$ & 4 & 9,5 \\
Total & & $\mathbf{4 2}$ & $\mathbf{1 0 0 , 0}$ \\
\hline
\end{tabular}

Berdasarkan tabel 1 diatas diketahui bahwa responden terbanyak termasuk pada kelompok usia $36-44$ sebanyak 24 orang (57.1\%), disusul kelompok usia kurang dari 36 tahun sebanyak 14 orang $(33,3 \%)$ dan paling sedikit dengan kelompok usia lebih dari
44 tahun sebanyak 4 orang $(9,5 \%)$. Berdasarkan data pada tabel 2 diketahui sebagian besar responden memiliki latar belakang S2 sebanyak 26 orang $(61,9 \%)$ dan paling sedikit dengan tingkat pendidikan SMA sebanyak 1 orang $(2,2 \%)$. 
Tabel 2. Distribusi Karakteristik Responden Berdasarkan Pendidikan

\begin{tabular}{cccc} 
No & Pedidikan & $\begin{array}{c}\text { Frekuensi } \\
(\mathrm{N})\end{array}$ & $\begin{array}{c}\text { Persen } \\
(\%)\end{array}$ \\
\hline 1 & SMA & 1 & 2,2 \\
2 & D3 & 2 & 4,8 \\
3 & S1 & 13 & 31,0 \\
4 & S2 & 26 & 61,9 \\
Total & & $\mathbf{4 2}$ & $\mathbf{1 0 0 , 0}$ \\
\hline
\end{tabular}

Tabel 3. Distribusi Karakteristik Responden Berdasarkan Jabatan

\begin{tabular}{cccc}
\hline No & Jabatan & $\begin{array}{c}\text { Frekuensi } \\
(\mathrm{N})\end{array}$ & $\begin{array}{c}\text { Persen } \\
(\%)\end{array}$ \\
\hline 1 & Staff & 13 & 31,0 \\
2 & Dosen & 29 & 69,0 \\
Total & & $\mathbf{4 2}$ & $\mathbf{1 0 0 , 0}$ \\
\hline
\end{tabular}

Berdasarkan data pada tabel 3 diketahui bahwa responden sebagian besar bekerja sebagai dosen sebanyak 29 orang dengan persentase (69\%) dan sisanya sebagai staf sebanyak 13 orang dengan persentase (31\%). Berdasarkan data pada tabel 4 diketahui mayoritas pegawai wanita di Universitas Malahayati memiliki konflik peran ganda yg rendah dengan jumlah frekuensi 18 orang $(42,9 \%)$, sedang 17 orang $(40,5 \%)$ dan tinggi 7 orang $(16,7 \%)$.

Tabel 4. Kategorisasi Konflik Peran Ganda

\begin{tabular}{cccc}
\hline No & Konflik Peran Ganda & $\begin{array}{c}\text { Frekuensi } \\
(\mathrm{N})\end{array}$ & $\begin{array}{c}\text { Persen } \\
(\%)\end{array}$ \\
\hline 1 & Rendah & 18 & 42,9 \\
2 & Sedang & 17 & 40,5 \\
3 & Tinggi & 7 & 16,7 \\
Total & & $\mathbf{4 2}$ & $\mathbf{1 0 0 , 0}$ \\
\hline
\end{tabular}

Tabel 5. Kategorisasi Stres Kerja

\begin{tabular}{cccc}
\hline No & Stress Kerja & $\begin{array}{c}\text { Frekuensi } \\
(\mathrm{N})\end{array}$ & $\begin{array}{c}\text { Persen } \\
(\%)\end{array}$ \\
\hline 1 & Rendah & 5 & 11,9 \\
2 & Sedang & 26 & 61,9 \\
3 & Tinggi & 11 & 26,2 \\
Total & & $\mathbf{4 2}$ & $\mathbf{1 0 0 , 0}$ \\
\hline
\end{tabular}

Berdasarkan data pada tabel 5

sedang sebanyak 26 orang $(61.9 \%)$ diketahui bahwa stres kerja pada tinggi sebanyak 11 orang $(26,2 \%)$ dan pegawai wanita di Universitas rendah sebanyak 5 orang $(11,9 \%)$.

Malahayati berada pada kategori

Tabel 6. Hasil Uji Normalitas Konflik Peran Ganda Kolmogorov-Smirnova Shapiro-Wilk Statist Statist

\begin{tabular}{lllllll} 
& ic & Df & Sig. & ic & df & Sig. \\
\hline Xkpg & .134 & 42 & .057 & .931 & 42 & .014
\end{tabular}

a. Lilliefors Significance Correction 
Berdasarkan hasil uji normalitas di atas menunjukkan bahwa skala konflik peran ganda mempunyai nilai $\mathrm{p}=0.057$. Asumsi normalitas pada sebaran variabel di atas terdistribusi dengan normal.

\section{Tabel 7. Hasil Uji Normalitas Stres Kerja}

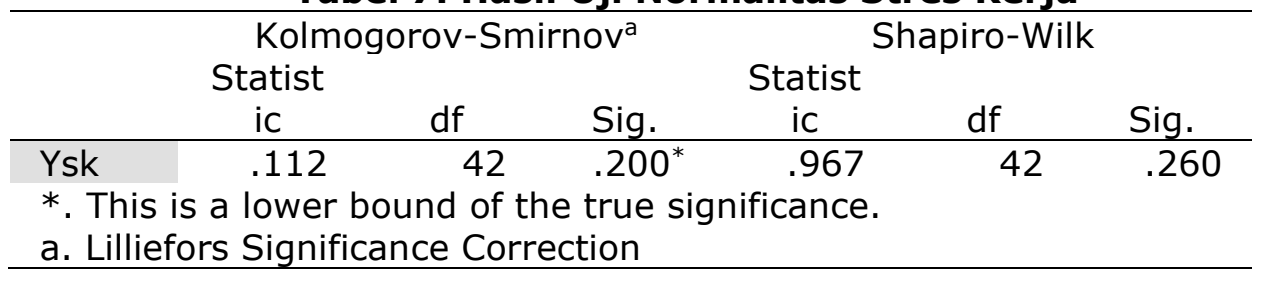

Berdasarkan hasil uji normalitas di atas menunjukkan bahwa skala Stres Kerja mempunyai nilai $p=0,200$.
Asumsi normalitas pada sebaran variabel di atas terdistribusi dengan normal.

Tabel 8. Hasil Uji Linearitas

\begin{tabular}{|c|c|c|c|c|c|c|c|c|}
\hline & & .719 & .719 & .719 & $\mathrm{~F}$ & Sig. & $\mathrm{R}$ & $\begin{array}{l}\text { R. } \\
\text { Square } \\
\text { d }\end{array}$ \\
\hline \multirow{3}{*}{$\begin{array}{l}\text { Between } \\
\text { Groups }\end{array}$} & & & & 136.043 & 3.889 & .003 & .719 & .518 \\
\hline & Linearity & 1997 & 1 & 1997.912 & 57.120 & .000 & & \\
\hline & $\begin{array}{l}\text { Deviation } \\
\text { from } \\
\text { Linearity }\end{array}$ & $\begin{array}{l}1267 \\
.114\end{array}$ & 23 & 55.092 & 1.575 & .170 & & \\
\hline
\end{tabular}

Berdasarkan hasil uji linearitas di atas menunjukkan bahwa korelasi antara konflik peran ganda dan stres kerja pada Deviation From Linearity dikolom sig, 0.170 dimana $\mathrm{R}=0.719 \mathrm{R}$ Square $=0.518$.

Tabel 9. Hasil Uji Hipotesis

\begin{tabular}{llcr}
\hline \multicolumn{2}{c}{ Correlations } & Ysk \\
\hline Xkpg & Xkpg & $.719^{* *}$ \\
& Corrson & 1 & .000 \\
& Sig. (2-tailed) & & 42 \\
Ysk & $\mathrm{N}$ & 42 & 1 \\
& Pearson & $.719^{* *}$ & \\
& Correlation & .000 & 42 \\
& Sig. (2-tailed) & 42 & \\
**. Correlation is significant at the 0.01 level (2-tailed). &
\end{tabular}

Hasil analisis data di atas menunjukkan bahwa Rxy 0.719 dengan Sig 0.000 dimana $p<0.000$ artinya ada hubungan antara variabel $X$ (konflik peran ganda) dengan variabel Y (stres kerja) pada pegawai wanita yang sudah menikah di Universitas Malahayati. Berdasarkan hasil analisis tersebut dapat disimpulkan bahwa hipotesis yang diajukan dalam penelitian ini dapat diterima. 


\section{PEMBAHASAN}

Hasil penelitian menunjukkan bahwa ada hubungan konflik peran ganda dengan stres kerja. Sedangkan untuk hipotesis dapat disimpulkan bahwa "Ada hubungan antara konflik peran ganda dengan stres kerja pada pegawai wanita yang sudah menikah di Universitas Malahayati sehingga hipotesis $\mathrm{H}_{\mathrm{a}}$ diterima". Hasil uji korelasi yang menunjukkan adanya hubungan antara konflik peran ganda dengan stres kerja pada pegawai wanita yang sudah menikah ( $r=0,719)$. Hasil penelitian yang sudah dilakukan oleh peneliti sejalan dengan hasil penelitian yang dilakukan oleh Wulandari \& Retno (2014) dimana meneliti tentang "Hubungan Antara Konflik Peran Ganda Dengan Stres Kerja Pada Perawat Wanita Yang Sudah Menikah di RSUD Banyumas", dan didapatkan hasil bahwa terdapat hubungan antara konflik peran ganda dengan stres kerja pada pegawai wanita yang sudah menikah dimana semakin tinggi konflik peran ganda maka semakin tinggi stres kerja, sebaliknya semakin rendah konflik peran ganda semakin rendah stres kerja (Wulandari D \& Retno D, 2014).

Kategorisasi secara empirik dalam penelitian ini diperoleh hasil untuk variabel konflik peran ganda yaitu subjek yang memiliki konflik peran ganda yang rendah berjumlah 18 orang $(42,9 \%)$ dan subjek yang memiliki konflik peran ganda yang sedang berjumlah 17 orang $(40,5 \%)$, sedangkan yang memiliki konflik peran ganda yang tinggi berjumlah $7(16,7$ $\%)$ yang artinya sebagian besar pegawai wanita yang sudah menikah di Universitas Malahayati memiliki tingkat konflik peran ganda yang rendah.

Berdasarkan hasil penelitian terhadap aspek-aspek dari konflik peran ganda pada pegawai wanita yang sudah menikah di Universitas Malahayati didapatkan hasil yaitu pada aspek time-based conflict, berada dalam kategori rendah berjumlah 21 orang dengan persentase $50 \%$, aspek strain-based conflict, berada dalam kategori sedang berjumlah 28 orang dengan persentase $66,7 \%$, aspek behavior-based conflict, berada dalam kategori sedang berjumlah 20 orang dengan persentase $47,6 \%$.

Berdasarkan hasil penelitian terhadap aspek-aspek dari stress kerja pada pegawai wanita yang sudah menikah di Universitas Malahayati didapatkan hasil yaitu pada aspek fisiologis yang berada dalam kategori sedang dengan jumlah 21 orang dan persentase $50 \%$, pada aspek psikologis dalam kategori sedang dengan jumlah 25 orang dan persentase 59,9\%, aspek tingkah laku berada pada kategori sedang dengan jumlah 23 orang dan persentase $54,8 \%$, dan pada aspek organisasional juga berada pada kategori sedang dengan jumlah 29 orang dan persentase $69 \%$.

\section{KESIMPULAN}

Berdasarkan hasil penelitian dapat disimpulkan bahwa ada hubungan antara konflik peran ganda dengan stres kerja pada pegawai wanita yang sudah menikah di universitas Malahayati, dengan nilai korelasi sebesar 0,719 yang artinya semakin tinggi konflik peran ganda maka semakin tinggi stres kerja. Sebaliknya semakin rendah konflik peran ganda maka semakin rendah stres kerja.

\section{SARAN}

Diharapkan Institusi dapat membuat pelatihan-pelatihan atau seminar tentang konflik peran ganda dan stress kerja untuk pegawai wanita, dapat mempertimbangkan untuk kenaikan gaji pegawai di Universitas Malahayati agar dapat meminimalisirkan tingkat stress kerja pada pegawai.

\section{UCAPAN TERIMAKASIH}

Saya ucapkan terima kasih kepada Universitas Malahayati dan pegawai wanita yang sudah menikah karena telah mendukung 
danmembantu saya menyelesaikan penelitian ini.

\section{DAFTAR PUSTAKA}

Frone, M.R. 2010. Work-Family conflict and Employee Psychiatric Disorders: the National comorbidity Survey. Dalam Journal of Applied Psychology. 85 (6) : 888-895.

Hotma \& Minarsih. 2011. Pengaruh stres kerja terhadap komitmen organisasi.(TA No. 0612010135/FE/EM/2011).Unpu blished undergraduate. Tesis. Universitas Pembangunan Nasional Veteran Surabaya.

Keenan, A., Newton, T. J., \& Logue, C. 1986. Work needs, sex role stereotyping and affective reactions of female professional engineers. Journal of Occupational Behaviour.

Kinnunen, U., Feldt, T., Geurts, S,dkk. 2006. "Types of Work-Family Interface: Well-Being Correlates of Negative and Positive Spillover Between Work and Family." Scandinavian Journal of Psychology, 47, 149-162.
Martini, A. Nina. 2017. Psikologi. Tangerang Selatan: Universitas Terbuka. ISBN 9787970114678

Prihatini, L.D. 2017. Analisis Hubungan Beban Kerja dengan Stres Kerja Perawat di Tiap Ruang Rawat Inap RSUD Sidikalang. Skripsi. Universitas Sumatera Utara Medan.

Rice, Robbins, S. (1999).Perilaku Organisasi (Konsep, Kontroversi dan Aplikasi).Jilid dua.Jakarta : Prehallindo.

Sugiyono. 2012. Memahami Penelitian Kualitatif. Bandung: ALFABRTA

U.S Cencus Bureau. 2003. Gender Differences in the Importance of Work and Family Roles: Implications for Work-family Conflict. Sex Roles, Vol. 47, No. $11 / 12$.

Wulandari, D., Retno, D. 2014. Hubungan Antara Konflik Peran Ganda Dengan Stres Kerja Pada Perawat Wanita Yang Sudah Menikah. PSYCHO IDEA, Tahun 12. No.2, 33-41. 